The Journal of Laryngology \& Otology

http://journals.cambridge.org/JLO

Additional services for The Journal of Laryngology \& Otology:

Email alerts: $\underline{\text { Click here }}$

Subscriptions: $\underline{\text { Click here }}$

Commercial reprints: Click here

Terms of use : $\underline{\text { Click here }}$

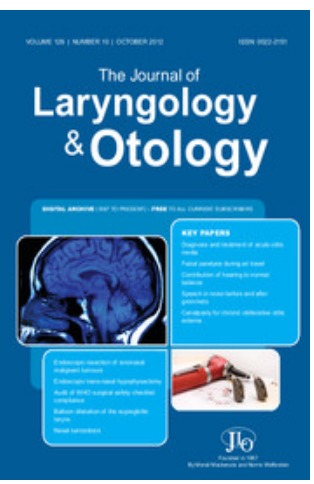

\title{
Spontaneous dissection of the intrapetrous internal carotid artery
}

S. R. Saeed, A. E. Hinton, R. T. Ramsden and R. H. Lye

The Journal of Laryngology \& Otology / Volume 104 / Issue 06 / June 1990, pp 491 - 493

DOI: 10.1017/S0022215100112964, Published online: 29 June 2007

Link to this article: http://journals.cambridge.org/abstract_S0022215100112964

How to cite this article:

S. R. Saeed, A. E. Hinton, R. T. Ramsden and R. H. Lye (1990). Spontaneous dissection of the intrapetrous internal carotid artery. The Journal of Laryngology \& Otology, 104, pp 491-493 doi:10.1017/S0022215100112964

Request Permissions : $\underline{\text { Click here }}$ 


\title{
Spontaneous dissection of the intrapetrous internal carotid artery
}

\author{
S. R. Saeed, F.R.C.S. ,† A. E. Hinton F.R.C.S. ,† R. T. Ramsden F.R.C.S.,† R. H. Lye F.R.C.S.* (Manchester)
}

\begin{abstract}
Two cases of cervicocephalic arterial dissection of the intrapetrous carotid artery are described. One patient presented with intolerable objective pulsatile tinnitus, the other with a cerebral infarction. Both were successfully treated with anticoagulants. The significance of minor degrees of trauma and of neck extension in the aetiology of these apparently spontaneous lesions is discussed.
\end{abstract}

\begin{abstract}
Introduction
Cervicocephalic arterial dissection (CCAD) is a relatively rare, but increasingly recognized cause of acute stroke. In many instances there is an identifiable aetiological factor such as disease of the arterial wall, or external or penetrating trauma to the vessel, but just as frequently there is no obvious cause and these lesions have been regarded as spontaneous. The significance of minor degrees of trauma in such cases has recently been re-emphasized by Trosch et al. (1989). Two patients with CCADs of the intrapetrous portion of the internal carotid artery following trivial trauma are described, presenting with totally different clinical syndromes.
\end{abstract}

\section{Case Reports \\ Case 1}

A 42-year-old woman experienced the sudden onset of pulsatile tinnitus in her right ear some twenty-four hours after the development of a severe occipital headache. For two days prior to the commencement of her symptoms she had been redecorating her home, and spent several hours repapering and painting her ceiling, with her neck extended. The tinnitus rapidly increased in intensity and became so intolerable that she became acutely agitated, and had been unable to sleep for almost two weeks. She experienced no other otological symptoms and had had no problems with her balance. She was an otherwise fit person with no history of otological, neurological or vascular disease. On examination there was no abnormality to be seen in the ears, and she was neurologically intact. The blood pressure and cardiac rhythm were also normal. A harsh rasping pulsatile bruit was clearly audible on auscultation of the right side of the neck, face, ear and forehead and was loudest in the temporal region.

Pure tone audiometry revealed normal hearing on both sides, but tympanometry yielded a pulsatile tracing synchronous with the arterial pulse. A CT scan with contrast was normal and carotid angiography was performed. This revealed a subintimal dissection of the intrapetrous portion of the right internal carotid artery (Fig. 1) but minimal narrowing of the lumen.

Treatment was commenced with anticoagulants, sodium heparin 40000 iu per day for forty-eight hours and oral sinthrome. In addition, the patient was heavily sedated to allow her to sleep. Within twenty-four hours there had been a very marked decrease in the intensity of the tinnitus, to the extent that it was tolerable and there was a considerable improvement in her psychological state and she was discharged home two days later on oral anticoagulants. At review one month later, she was symptom free and the treatment was discontinued. One year later she has had no recurrence of her tinnitus.

\section{Case 2}

A 42-year-old male presented with left frontal headache and with numbness and weakness of the right upper and lower limbs. These symptoms developed some hours following a game of badminton during which he felt light headed, was aware of a transient blurring of vision in the left eye, and noticed that he was unable to articulate clearly. There was no loss of consciousness. There was no hearing loss and no tinnitus. On examination he was found to have marked weakness of the right shoulder and elbow, and of a lesser degree in the right hand. Right sided hip, knee and ankle movements were weak. Depressed pinprick sensation was demonstrable on the right side in the dermatomes C2-T4. There was no neck stiffness. Examination of the cardiovascular system failed to reveal any abnormality. There was no bruit audible in the neck.

Lumbar puncture was performed and examination of the CSF was normal. CT scan suggested a left temporoparietal infarction but was inconclusive. Digital angiography (DART and DIVA) showed the appearance of a spontaneous dissection of the internal carotid artery in its intrapetrous section with severe concentric stenosis at that level (Fig. 2).

Treatment with anticoagulants was initiated (Heparin 30000 iu over twenty-four hours followed by Warfarin for a period of three months). During the first two weeks following the commencement of treatment, there was a steady improvement in both the sensory and motor dysfunction, and after three months he has made an almost total recovery.

\section{Discussion}

Cervicocephalic arterial dissection is a relatively uncommon cause of acute stroke. In a ten year study in which angiography was carried out in 4,531 cases of stroke, no more than nineteen instances $(0.4 \%)$ of dissection were detected (Biller et al., 1986). Of these sixteen were extracranial, but in none of the cases was the intrapetrous segment of the internal carotid specifically mentioned as the site of the dissection. O'Connell 


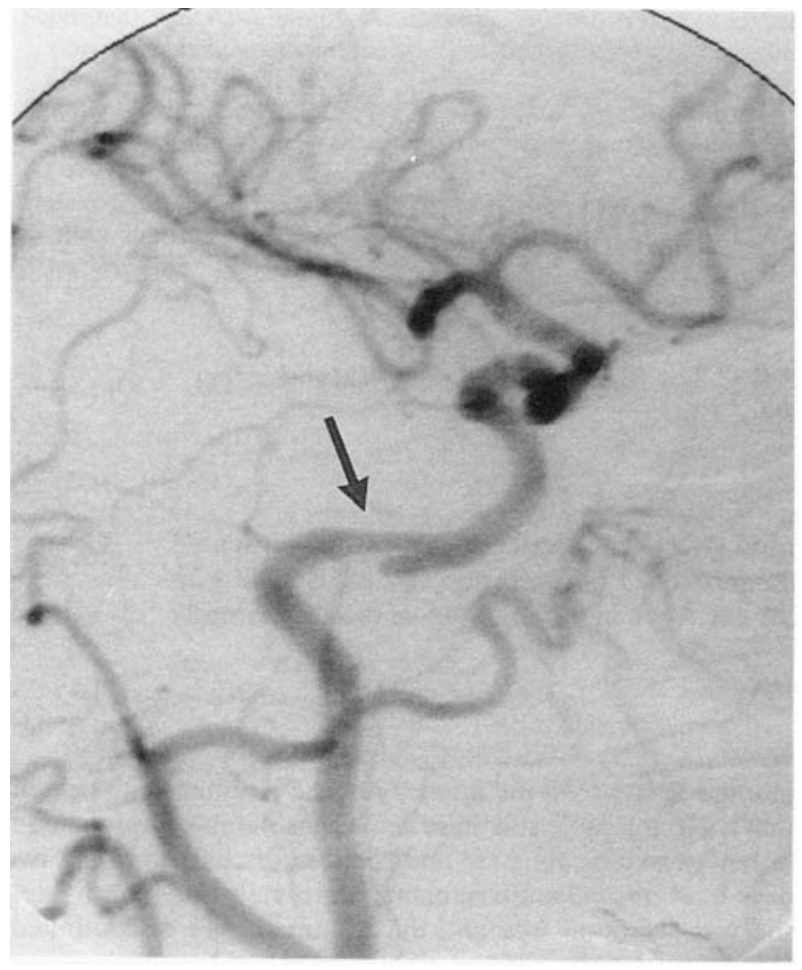

FIG. 1

Right carotid angiogram showing dissection of the intrapetrous segment of the internal carotid artery.

et al. (1985) reviewed 51 cases of CCAD in which full surgical or post mortem data were available and came to a number of conclusions. In general, extracranial dissection tends to be commoner in older patients (average age 52 years) and is usually characterized by medial dissection which is secondary to arteriosclerosis, fibromuscular dystrophy or cystic medial necrosis in two-thirds of cases. Intracranial dissection, which carries a graver prognosis, tends to be a disorder of younger adults (average age 27 years) and is more likely to occur in the subintimal plane. It is clear that many dissections occur in apparently healthy vessels. At the onset of the dissection, symptoms may be minor and transient but as the dissection develops the arterial lumen narrows and may occlude and patients commonly present with ischaemic infarction.

Dissections which are not obviously caused by vascular disease or by major blunt or penetrating trauma have tended to be labelled as 'spontaneous'. Trosch et al. (1989) have recently re-emphasized the fact that very minor degrees of trauma may appear to be responsible for many of these 'spontaneous' extracranial dissections. They postulate that in certain circumstances sudden hyperextension of the neck may cause fixation of the internal carotid artery against the transverse process of C2. When this is accompanied by rotation of the neck, internal tearing of the vessel may ensue. They quote examples from the literature of dissection following such everyday activities as shaving, eating (Fisher et al., 1978), coughing, nose blowing, and certain sporting pursuits (Hart and Easton, 1982), as well as the more strenuous effort of childbirth (Wiebers and Mokri, 1985). Trosch et al. add their own case of spontaneous dissection of the internal carotid artery following repeated hyperextension of the neck in what they call a 'bottoms up' drinking ritual in a healthy young woman. In Case 1 described in this paper, the prolonged hyperextension of the neck associated with decorating a ceiling would appear to have been the precipitating factor, whereas in the second patient it was related to sporting activity, with presumably repeated episodes of craniocervical extension.

Pulsatile tinnitus is not a particularly uncommon complaint.
It is caused by turbulence in the flow of arterial blood, usually in part of the carotid tree. In older people that turbulence is usually set up by blood flowing over atherosclerotic lesions. When one considers the proximity of the intrapetrous carotid artery to the cochlea, it is easy to understand how turbulence may be transmitted to the ear as sound. A developing dissection initiates turbulence in the blood flowing past it and the patient experiences tinnitus, as in Case 1. In most instances a progressive process of obliteration occurs and blood flow in the vessel ceases with consequent infarction. In the absence of blood flow tinnitus will not be heard and this was the case in the second patient described. Other uncommon causes of pulsatile tinnitus include AV fistula of the posterior fossa dura (Arenberg and McCreary, 1971), or between the occipital artery and the lateral sinus (Morrison, 1989; Courteney Harris et al., 1990), and of course vascular temporal bone tumours such as those of the glomus jugulare. The increasing availability of digital contrast radiology has made evaluation of the symptom more straightforward, although it would seem excessive to subject all patients with pulsatile tinnitus to the investigation. Sudden onset of the tinnitus particularly in a young person, a history of trauma or of sudden or prolonged neck extension, or the coexistence of other otological, neurological or cardiovascular abnormalities might indicate those patients worthy of further investigation.

The usual management of CCADs has been aimed at the prevention of propagation of thrombus and distal embolization. To this end most authors have advocated the use of heparin with or without oral anticoagulants, although this regimen has not been demonstrated prospectively to be of significant value. In Case 1 the anticoagulants were prescribed with the specific intention of reducing the viscosity and thus the turbulence of the blood and so diminish the tinnitus. In this it was rapidly and completely successful. In due course these dissections tend to heal and occluded vessels often recanalize within six months (Bogousslavsky et al., 1987).

In view of the fact that the prognosis from most extracranial dissections is favourable, the vascular pathology in 'spontaneous' cases will remain elusive, and the role of minor everyday activities in their initiation will remain a matter of

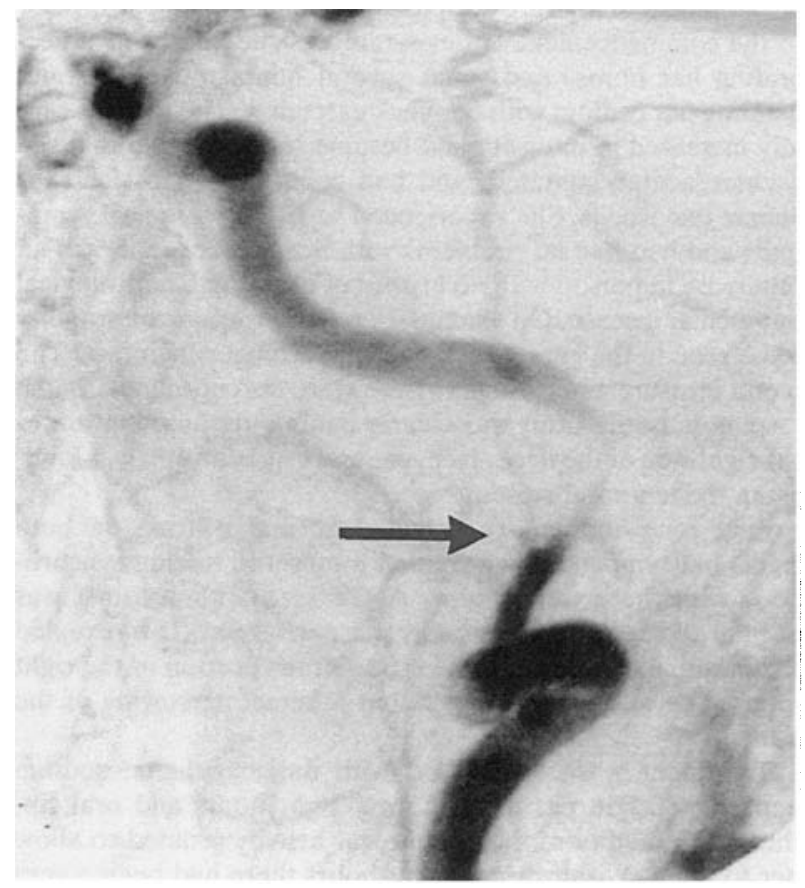

FIG. 2

Left carotid angiogram showing stenosis of the internal carotid artery. There is no flow of contrast past the stenosis. 
conjecture. There is a good case, however, for prospective evaluation of different treatment modalities, particularly since, with the increasing use of digital angiography, an increasing number of young adults presenting with acute stroke will be recognized as having suffered an arterial dissection of the craniocervical junction.

\section{Acknowledgements}

We would like to thank Dr R. Fawcitt, Consultant Radiologist, and Dr W. Schady, Consultant Neurologist for their advice and Miss J. Rich for secretarial assistance.

\section{References}

Arenberg, I. K., McCreary, H. S. (1971) Objective tinnitus aurium and dural arteriovenous malformation of the posterior fossa. Annals of Otology, Rhinology and Laryngology, 80: 111-21.

Biller, J., Hingtgen, W. N., Adams, H., Smoker, W., Godersky, J. C., Toffol, G. J. (1986) Cervicophalic arterial dissections. A ten-year experience. Archives of Neurology, 43: 1234-38.

Bogousslavsky, J., Despland, P. A., Regli, F. (1987) Spontaneous carotid dissection with acute stroke. Archives of Neurology, 44: $137-40$.
Courteney Harris, R. G., Ford, G. R., Innes, A. J., Colin, J. F. (1990) Pulsatile tinnitus: Three cases of arteriovenous fistula treated by ligation of the occipital artery. Journal of Laryngology and Otology, 104.

Fisher, C. M., Ojemann, R. G., Roberson, G. H. (1978) Spontaneous dissection of cervico-cerebral arteries. Le Journal Canadien des Sciences Neurologiques, 5: 9-19.

Hart, R. G., Easton, J. D. (1983) Dissections of cervical and cerebral arteries. Clinical Neurology, 1: 155-82.

Morrison, G. A. J. (1989) Pulsatile tinnitus and dural arteriovenous malformation. Journal of Laryngology and Otology, 103: 1073-5.

O'Connell, B. K., Towfighi, J., Brennan, R. W., Tyler, W., Matthews, M., Weidner, W. A., Saul, R. F. (1985) Dissecting aneurysms of head and neck. Neurology, 35: 993-7.

Trosch, R. M., Hasbani, M., Brass, L. M. (1989) 'Bottoms Up' dissection. New England Journal of Medicine, 1564-5.

Wiebers, D. O., Mokri, B. (1985) Internal carotid artery dissection after childbirth. Stroke, 16: 956-9.

Address for correspondence:

Mr S. R. Saeed, F.R.C.S.

Department of Otolaryngology

Manchester Royal Infirmary

Oxford Road

Manchester M13 9WL 